\title{
Forming Small Diameter Holes in Tungsten - Cobalt Alloys
}

\author{
Svetlana Vasilevskaya ${ }^{1}$, Konstantin Rakhimyanov ${ }^{1}$, Alexandra Ukraintseva $^{1}$ \\ ${ }^{1}$ Novosibirsk State Technical University, Faculty of Mechanical Engineering and Technologies, \\ 630073 Prospect K. Marx, 20, Novosibirsk, Russia
}

\begin{abstract}
The perspectives of combining the processes of electrochemical dissolving and electro-erosive removal of the processed material in forming small diameter holes in alloy WC-8Co by a hollow electrode-tool are presented in the paper. It is established that in using immovable electrodes forming the cone in the hole takes place. The dependence of the piercing depth change on time is obtained. It testifies the decrease in the processing speed with increasing the inter-electrode gap. It is shown that during the electro-erosive - electrochemical process with immovable electrodes the productivity of small diameter hole piercing increased by 3 times in comparison with the electrochemical processing.
\end{abstract}

\section{Introduction}

The development of science and technology in modern machine building, aircraft engineering, shipbuilding, car industry, cosmic and medicine branches impose new requirements for forming the surfaces differing both in dimension and in geometry. A special attention is given to forming small diameter holes in the range of $0.3 \mathrm{~mm}$ to $1 \mathrm{~mm}$. The holes in the diameter range mentioned present channels for supply and diffusion of different liquids, air and for lubrication and cooling. Such channels are used in various branches of modern industry for manufacturing the turbine blades, injectors, filiers, nozzles as well as medical devices. While using the devices mentioned, it is necessary that the channels were made according to high technological requirements concerning both the accuracy and quality of the surface. It is impossible to obtain small holes in the diameter range of $0.3 \mathrm{~mm}$ to $1 \mathrm{~mm}$ in hard alloy parts by using traditional methods of the mechanical processing [1-3].

Forming the holes of the dimension range mentioned in difficult-to process materials is possible by using electro-physical technologies, particularly the electro-erosive processing based on the destruction of the detail material influenced by the electrical discharge $[4-6]$. The method presented is one of the perspective and fast developing for obtaining the holes with the diameter dimensions less than $1 \mathrm{~mm}$.

In spite of the results achieved in obtaining small diameter holes in details made of similar materials with using the electro-physical processes, there are certain limitations in 
providing a high accuracy of forming. It is connected with a considerable value of electrode-tool wearing and obtaining low undulation of the processed surface [7]. The formation of the thermal influence zone and tension residual stresses related to the thermal mechanism of removing the processed material [8] is considered as a negative factor during the electro-erosive processing.

One more type of electro-physical technologies is the electrochemical dimension processing based on the local anode dissolving of the processed material. This method provides a high accuracy of the material processing and allows obtaining low undulation of the processed surface. The electrochemical dimension processing is widely used in technological processes of forming different surfaces as well as for the hole piercing in details produced from tungsten - cobalt alloys. The independence of material processibillity on their mechanical and thermo-physical properties as well as the absence of the electrode tool wearing makes the electrochemical dimension processing attractive for solving difficult technological tasks. However, forming the small diameter holes by this method is accompanied by some limitations connected with low processing efficiency.

Increasing the productivity of piercing small diameter holes is possible in combining the electrochemical dimension processing and the electro-erosive processing. Despite the differences in the mechanisms of removing the processed material, the development of these processes in their combining can be considered from common physical and chemical positions [9]. The use of such a processing for forming the holes in different materials allows increasing the productivity to 10 times in comparison with the electrochemical dimension processing [10 - 12].

The paper under consideration suggests assessing the intensification of forming the small diameter holes in the range of $0.3 \mathrm{~mm}$ to $1 \mathrm{~mm}$ in processing the alloy WC-8Co by the electro-erosive - electrochemical influence with immovable electrodes.

\section{Theoretical and Experimental Investigations}

It is known that hard alloys of WC-Co group consist of two phases: the cobalt binding material and the grains of the implementation phase distributed in it - tungsten carbide [13]. To process such a material, it is necessary to choose the optimal composition of the electrolyte in which both phases with different electrochemical properties are dissolved at the same speed. To process the materials of such a kind complex electrolytes are used, namely multicomponent alkali-salt solutions with a high value $\mathrm{pH}[14-17] .10 \% \mathrm{NaNO}_{3}+$ $10 \% \mathrm{NaOH}$, where $\mathrm{NaNO}_{3}$ - the aqua solution of sodium nitrate (salt) and $\mathrm{NaOH}$ - sodium hydroxide (alkali) were used as an electrolyte in the present investigation. Neutral salt solutions influence the cobalt dissolving favorably $[18,19]$ during the processing but it is known that in them the tungsten carbide is easily passivated. For this reason, concentrated alkali solutions are used to dissolve tungsten carbide [20,21]. During the processing cobalt starts passivating in one-component alkali solutions. Salts of alkali metals (usually the nitrate or chloride of sodium) are added in the electrolyte composition for its activation. For the investigation, the hard alloy WC-8Co was chosen for forming the holes of the mentioned diameter range.

Experiments on forming the small diameter holes were made on a specially designed and manufactured installation, the description of which is presented in Paper [22]. The assessment of the results of hole forming in this material was made during the hole piercing according by using immovable electrodes [23]. Forming in the investigated material was conducted by the tube electrode - tool with a ratio of the outside and inside diameters $0.65 \mathrm{~mm} / 0.39 \mathrm{~mm}$. The electrolyte injection was accomplished at an excessive pressure $\mathrm{P}=$ $0.8 \mathrm{MPa}$; the technological voltage was equal to $\mathrm{U}=10 \mathrm{~V}$. The value of the pulse voltage $\left(\mathrm{U}_{\text {imp }}\right)$ was $350 \mathrm{~V}$ for a pulse duration $\tau_{\text {imp }}=4 \mu$ s and the pulse repetition period $\mathrm{T}=27.5$ 
$\mu$ s. The processing time during the electrochemical dimension processing was equal to 5 minutes and during the combined processing -1.5 minutes. The depth of the obtained holes in samples during the electrochemical dimension processing and the combined process was controlled by the indicator with a graduation mark of $0.002 \mathrm{~mm}$. The form and the diameter dimension of the hole were assessed by the measuring microscope Nikon MM -400 .

\section{Results and Discussion}

Figure 1 presents the photos of the holes obtained in the hard alloy WC-8Co during the electrochemical dimension processing (a) and the electro-erosive - electrochemical process (b)
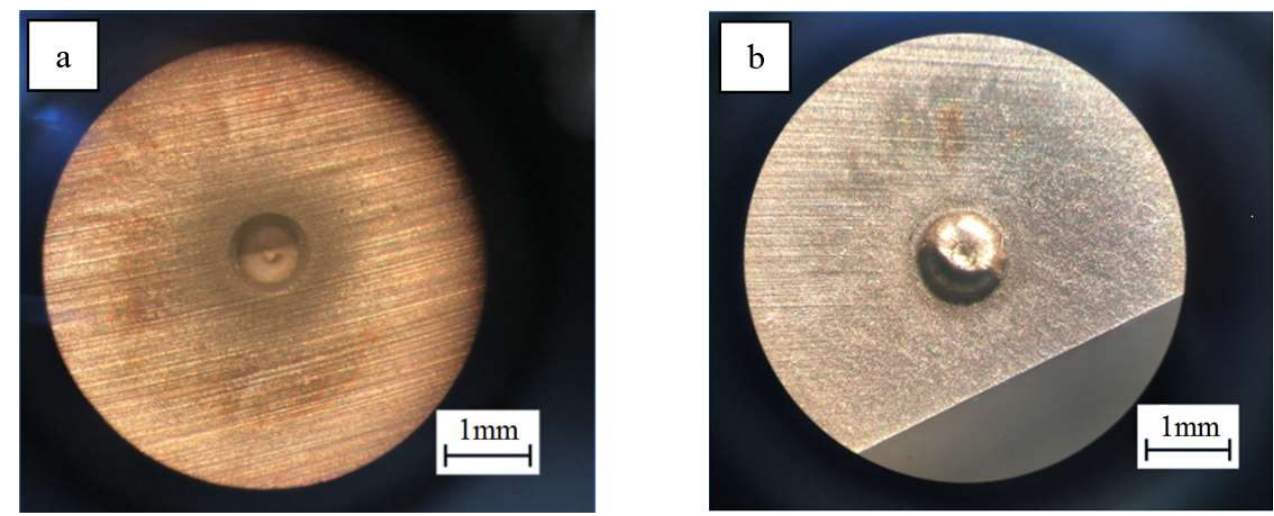

Fig. 1. View of the sample entrance hole: a) electrochemical dimension processing $(t=5 \mathrm{~min}) ; \mathrm{b})$ electro-erosive - electrochemical processing $(\mathrm{t}=1.5 \mathrm{~min})$

The formation of the cone in holes is established, which is typical of the processing by the immovable electrode-tool. In this case the diameter of the entrance hole during the electro-erosive - electrochemical processing was equal to $1.03 \mathrm{~mm}$ and during the electrochemical dimension processing $-0.86 \mathrm{~mm}$. The increase in the entrance diameter of the hole during the combined process can be explained by the simultaneous use of the two mechanisms of removing the material.

The decrease in the current density is observed with the hole deepening both during the electrochemical dimension processing and during the electro-erosive -electrochemical process, which does not allow maintaining the constant speed of the processing (Fig. 2). This can be explained by the fact that with deepening the hole the direct-current resistance of the electrolyte column increases with growing the inter-electrode gap.

Figure 3 presents the ratio of the hole piercing depth during the electrochemical dimension processing and during the electro-erosive - electrochemical process. The comparison of the results obtained under the same conditions (the electrolyte pressure, the electrolyte composition, the value of the inter-electrode gap, the electrode-tool dimension, the scheme of the immovable electrode-tool as well as technological modes of the electrochemical process) gives evidence that the implementation of the electro-erosive component in the electrochemical process provides the increase in the productivity by 3 times. 


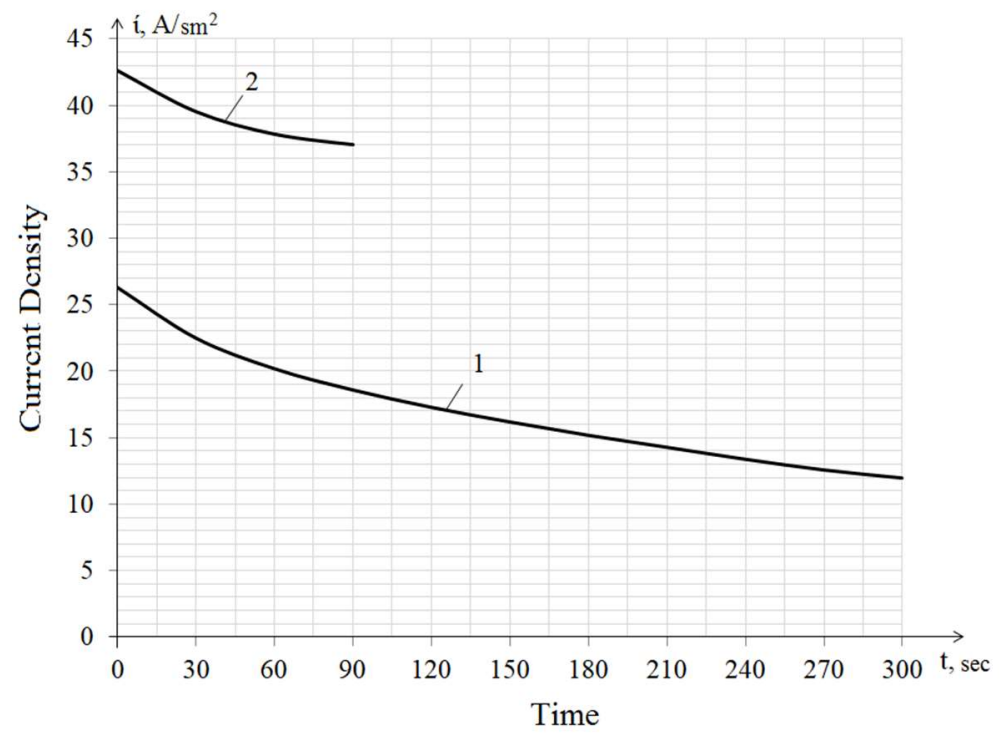

Fig. 2. Dependence of the current density on the processing time: 1 - electrochemical dimension processing 2 - electro-erosive - electrochemical processing

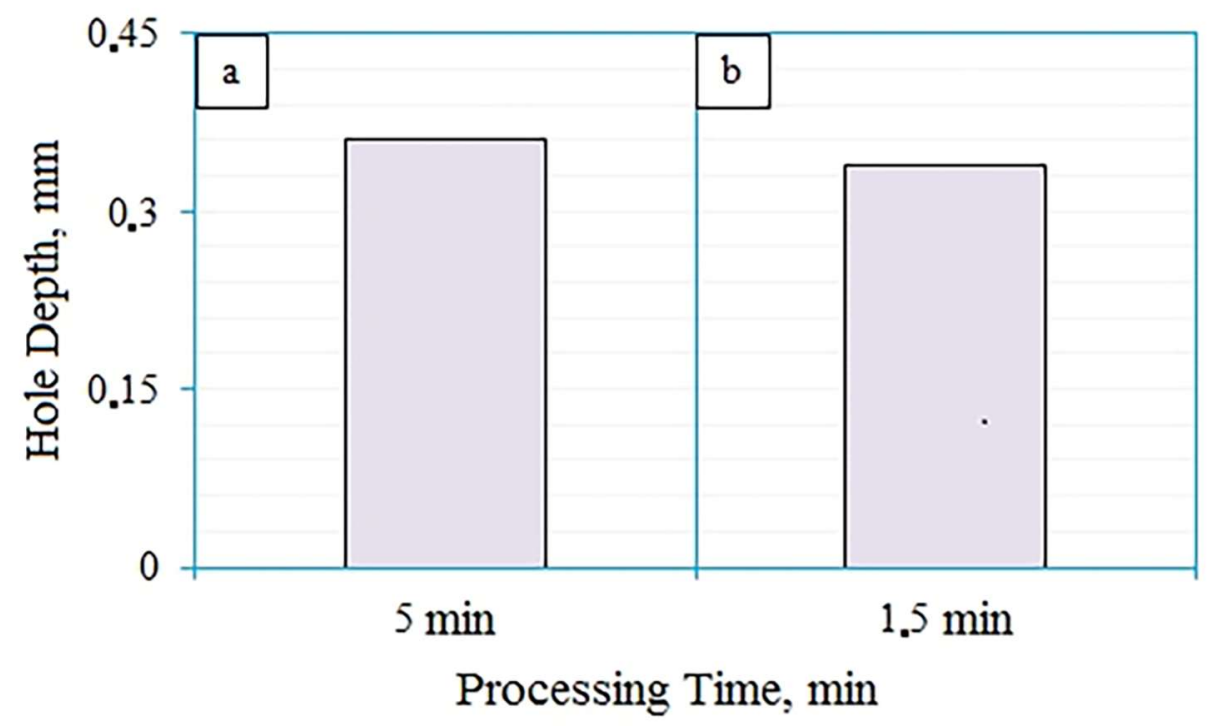

Fig. 3. Dependence of the hole depth on the processing time: a) electrochemical dimension processing electro-erosive - electrochemical processing

\section{Conclusions}

1. It is established that complex electrolytes are used for the uniform etching of alloy WC$8 \mathrm{Co}$ components in order to form the small dimension holes in the alloy mentioned. 
2. The experimental results showed the possibility of combining the electrochemical and electro-erosive processes in one processing for forming the holes with a diameter of less than $1 \mathrm{~mm}$ in the difficult-to process alloy WC-8Co.

3. It is established theoretically that in forming small dimension holes by a hollow immovable electrode-tool the appearance of the cone and the hole expansion at the entrance with deepening the processing depth both during the electrochemical dimension processing and during the combination of processes can be observed. It is also established that the current densities realized during the electrochemical dimension processing and the combined process constitute $26 \mathrm{~A} / \mathrm{sm}^{2}$ and $43 \mathrm{~A} / \mathrm{sm}^{2}$, respectively at the initial period of processing and then decrease after obtaining a depth of $1=0.36 \mathrm{~mm}$ and $1=0.34 \mathrm{~mm}$ to 19 $\mathrm{A} / \mathrm{sm}^{2}$ and $37 \mathrm{~A} / \mathrm{sm}^{2}$. It is shown that in combining the electro-erosive and electrochemical processes, even with immovable electrodes, the processing productivity increased by 3 times.

\section{References}

1. A.R. Maslov, A.G. Skhirtladze, Processing difficult-to-cut materials by cutting: a tutorial (Moscow, Mashinostroenie, 2018)

2. G.V. Borovsky, S.N. Grigoriev, A.R. Maslov, Modern materials processing technologies (Moscow, Mechanical Engineering, 2015)

3. V.Kh. Fidarov, Processing of blanks of machine parts from hard-to-machine materials, (2014)

4. T.R. Ablyaz, A.M. Khanov, O.G Khurmatullin, Modern approaches to the technology of electroerosive processing of materials: a tutorial (Perm: Publishing House Perm. nat researches Polytechnic University, 2012)

5. Yu.Yu. Eliseev, Electroerosive treatment of aerospace products (MSTU N.E. Bauman, Moscow, 2010)

6. M.Yu. Sarilov, Science and education, 3:83, 76 (2016)

7. J. Narasimhan, Z. Yu, K.P. Rajurkar, J Manuf Process, 7, 75 (2005)

8. K.P. Rajurkar, M.M. Sundaram, A.P. Malshe, The Seventeenth CIRP Conference on Electro Physical and Chemical Machining (ISEM), 6, 13 (2013)

9. B.R. Lazarenko, N.I. Lazarenko, Electronic processing of materials, 1, 5 (1978)

10. B.P. Saushkin, Electronic processing of materials, 1, 4 (2004)

11. Kh.M. Rakhimyanov, S.I. Vasilevskaya, High, critical electro-and nanotechnologies: Proceedings of the all-Russian scientific-technical conference, 62 (2017)

12. Kh.M. Rakhimyanov, I.A. Leontyev, S.I. Vasilevskaya, Science intensive technologies in mechanical engineering, 10:64, 7 (2016)

13. V.I.Tretyakov, Metal-ceramic hard alloys, (Moscow, Metallurgizdat, 1962)

14. Z.Y. Grodzinsky, L.I. Lomonosov, Electrolyte for electrochemical processing of hard alloys (ed. Swith, 313639, Bull. 1971)

15. V.V. Parshutin, Electrochemical dimensional processing of metals: (Shtiints publishing house, 117 (1974)

16. V.P. Kondratiev, Study of the technological features of the electrochemical flashing of small-diameter holes in hard alloys (author. dis. Cand. tech. sciences. Voronezh: 20 (1974)

17. G.A. Iskhakova, A.I. Kapustin, V.N. Filimonenko, Electrochemical treatment of metals (Novocherkassk, 1980)

18. Yu.N. Petrov, Electronic processing of materials, 2, 24 (1969)

19. J.P. Hoare, Nature (Engl.), 5158:219, 5 (1968)

20. K. Agte, I. Vacek, Wolfram and Molybdenum (Moscow, Leningrad - Energy, 1964) 
21. P.V. Schigolev, Electrolytic and chemical polishing of metals (Moscow, Publishing House of the Academy of Sciences of the USSR, 1959)

22. Kh.M. Rakhimyanov, S.I. Vasilevskaya, MATEC Web of Conferences, 224, 01013 (2018)

23. Kh.M. Rakhimyanov, S.I. Vasilevskaya, Metal Working and Material Science, 2:71, 12 (2016) 